\title{
Physico-Mechanical Properties of Plaster of Paris (Gypsum Plaster) Reinforced with Paper Pulp
}

\author{
Ngwe Nnoko Ngaaje
}

\begin{abstract}
The study was carried out on the physicomechanical properties of plaster of Paris (Gypsum plaster) reinforced with paper pulp in order to improve the weight of plaster paste and to obtain materials of lighter weight that solve problems such as poor flexural strength, and crack propagation. To do this experiment, the considerable basis of a standard of 2 kg of plaster of Paris was taken as the test sample. Gradually plaster of Paris was substituted with paper pulp paste in a water basin in proportions K0, K1, K2, K3, K4, K5 and $\mathrm{K6}$ representing the different percentages of $0 \%, 10 \%, 20 \%, 40 \%$, $60 \%, 80 \%, 100 \%$ of mixture respectively. After the above observations, the following parameters on fresh and hardened samples were tested: the start time of reaction, and end time of hardening, consistency, the flexural and compressive strength, shrinkage, and apparent density. At the end of these tests, it was determined that, the incorporation of small amounts of paper pulp ( $2 \mathrm{~kg}$ samples) into the plaster paste improves its flexural properties. But from $\mathrm{k0}$ to $\mathrm{k6}$, properties related to bending and compression began to gradually fall which is a consequence of the augmentation of the amount of paper paste in the plaster paste. The presence of paper pulp in the plaster of Paris paste increases the time of hardening of the plaster cement from one proportion to another, reduces the workability of the mixed paste, significantly solves the problem of removal, the apparent density drops when waste paper paste is increased in the mixed plaster.

Because of its light weight, low density, its acceptable Mechanical properties, these new materials are recommended for exploitation in the manufacturing of popular lightweight construction finishing like panels for ceiling or walls, staff works and other applications.
\end{abstract}

Index Terms - Physical properties, Mechanical properties, Plaster of Paris, Waste paper, Fibre (cellulose fibres.

\section{BACKGROUND OF THE STUDY}

The birth of the plaster is illustrated by a legendary tale which states that a young shepherd guarding his flock wanted to warm by the fire. He picked up wood and stones and pricked around his hearth. In the heat of the flame, the hearth stones were transformed into a white powder. The rain came and the powder was transformed into a paste. Then when the sun reappeared, the dough dried again, and to the surprise of the young shepherd became as hard as the original stone. Gypsum had delivered her secret: the plaster was born [1].

The plaster is known from the Neolithic period, about 9000BC. By this time, it was commonly used. The oldest discovery dates back to 7000 BC., on the site of Çatalhöyük (in Anatolia), where we find the plaster on the walls as a coating. The Sumerians, Assyrians and especially the Egyptians used a lot of Gypsum especially for making death masks of which the first known example is that of King Téty [1]. It was still in Egypt as gypsum production was the most important (reliefs, medallions, covesties, vase stands, dishes). With the Roman conquest, the cast arrived in Gaul. The technique took root very easily since the Paris Basin and other regions of Gaul had an abundance of gypsum. In Paris, the plaster stone was sometimes used as raw stone for building or in antiquity for plaster. In the Renaissance, it was only with the Florentine sculptor André we rediscovered the use of plaster for casting statutes, which constituted the royal and princely collections. Meanwhile the masks again became fashionable. But it is especially the nineteenth century that was the century with plaster moulding museums, when the plaster became a famous and popular building material in civil works.

Despite this good assessment, there remains dissatisfaction with the desire it arouses in its users: for example, it does not keep its qualities from the weather (humidity in particular), it is fragile and does not allow major stresses in bending or tension, it is expensive for users of the third world. Research in the direction of improvement in order to reduce his costs proves justified. Some of these researches have already been completed and published and studies are ongoing [2].

In Cameroon, the use of plaster is popular through moulding by artists in the production and installation of suspended ceilings (staff) and in the coating of interior walls. It is limited to civil works or works of prestige, certainly because of the high cost price: since all the components are imported. The plaster is mostly imported from France and Algeria [3]. If the reinforcement could be done locally, it would contribute to reducing the cost of the finished product. The use of reinforced plaster could then be diversified to include building of walls and have a new class of users in third world countries [4].

\section{CONTEXT OF THE STUDY}

This study was undertaken for several reasons including educational, environmental, technical, and socio-economic reason. In the technical and socioeconomic context, the first concern is to encourage the use of materials found locally from daily office and printing waste. Pedagogically, it is intended to contribute to the consideration and promotion of local materials for the training of apprentices and students. This piece of work will be useful for both students and teachers. Also, the importance of this research will not only provide a new type of construction material, but it will also

Published on January 26, 2021.

Ngwe Nnoko Ngaaje (PhD), Department of Mechanical Engineering ENSET

Kumba, University of Buea, Cameroon.

(e-mail: ngwengaaje ${ }^{\circledR}$ gmail.com) 
reduce the waste of resources, creating environmental awareness in the field of building materials. Technically, it will bring innovation in the field of plaster fillers and partitioning as the introduction of paper pulp from debris shows different effects on cracking of plaster.

\section{PROBLEM}

Plaster is very suitable for multiple new designs because of its many qualities. Not only can it be moulded in various forms, but it has excellent compression strength, high stiffness, low thermal, and electrical conductivity, it is fireproof and low in toxicity [5]. Two features nevertheless have limited its use: it is expensive and entirely imported into Cameroon. Recent development of composites reinforced with local materials in the area of Building and Public Works provided the opportunity to overcome these gaps particularly in the manufacture of lightweight panels [5]. Although plaster is an increasingly used building material nowadays, it is a rare and expensive in underdeveloped countries since the product is imported to these countries. To try to overcome these negative aspects, several methods have been devised including the addition of local materials in a cast, but no proper studies have been done on how its physical and mechanical properties are modified when these additions are done. There are currently a wide variety of composite materials. Most of them are intended for high-tech industries, they use composites made of local materials such as carbon fibers, alumina, waste paper, palm kernel shells, rice husk etc. The incorporation of locally available fibers in the plaster is done to reduce its cost [6].

The important assumption is that waste paper generally referred to as paper pulp when mixed with plaster of Paris, POP paste, hardens upon hydration exothermically, producing a lighter mass that can be moulded into different usable forms. This is due to the fact that paper, which is composed of vegetal material and animal cellulose, acts as an admixture to POP. In order to enhance the use of local materials, exploit waste and build at lower cost, this study is seeking means by which certain wastes containing vegetable or cellulose fibers like waste paper could be introduced in the formulation of plaster to offer similar properties as the pure POP. Therefore, this report is concentrated on the physicomechanical properties of POP reinforced with paper pulp. Does plaster get us a light material with acceptable physicomechanical properties once reinforced with paper pulp?

\section{OBJECTIVES OF THE RESEARCH}

\section{A. General Objective}

The general objective of this study is to determine the physico-mechanical properties of POP reinforced with Paper Pulp. This is to contribute to local development through the analysis of suitable local raw materials that can be combined with POP and the appropriate exploitation of POP in real life applications and propose solutions to solvable problems.

\section{B. Specific Objectives}

To achieve the overall objective, the following specific objectives are pursued:
- to evaluate the effect of paper pulp on the physical properties of plaster;

- to evaluate the effect of paper pulp on the mechanical properties of plaster;

- to identify the most locally used plaster applications and recommend suitable cost-effective mixtures for such applications.

\section{DEFINITION OF SOME IMPORTANT TERMS}

Plaster: Plaster is a building material used for coating walls and ceiling. Plaster starts as a dry powder similar to mortar or cement and like those materials it is mixed with water to form a paste which liberates heat and then hardens. [7].

Gypsum: Gypsum is a natural mineral or sedimentary rock, which settled through the evaporation of sea water, trapped in lagoons with chemical name calcium sulphate. Chemists write it as: $\mathrm{CaSO}_{4} \cdot 2 \mathrm{H}_{2} \mathrm{O}$ [7].

Gypsum plaster (Plaster of Paris): Gypsum plaster is a type of plaster or binder which can be used in art, architecture, fireproofing, and medical applications [2].

Binder: A binder is a material which acts as a glue or cement when mixed with aggregate (e.g., sand) and water to form a fresh plaster, render mortar or concrete [2].

Light Panels: it is a developed product that applies to a vast range of constructions; it is a revolutionary material in the construction trade, especially prefabrication. It is generally used for walls, ceiling etc., in short it is used like filler block in building and is very appropriate for light constructions [3].

Mortar: is a homogeneous mixture in well-defined proportions of sand, cement, and water [3].

Vegetable fibres: they are the filaments of the plants made up of a cellulose fibres chain. They are naturally wet, their chemical composition being made of three principal components namely: the cellulose, hemicelluloses, and lignin [7].

\section{PRACTICAL APPLICATIONS OF RECYCLED WASTE MATERIALS}

The volumes of waste being generated in any city, and that must be collected and disposed of, require ever increasing funds to manage it and it is also creating increasing environmental concerns. In the developing world reclamation of recyclable waste products from the municipal waste stream has become an important source of revenue for many people who cannot find formal employment and it is their only source of income. This in effect creates informal jobs for many.

Some daily uses of recycled waste material include:

\section{Construction of Asphalt Pavements}

Asphalt road pavements form a significant value in the road network of many cities. As original material gets expensive and exhausted, the best resort is recycling waste into these pavements. The materials that can be suitable for this include glass, steel slag, tires, and plastics, and depend on various factors such as: mixture types, particle size of 
recycled waste types and replacement rate; and the nature and processing techniques for the waste types (e.g., weathering for steel slag). When plastic is used, it is called asphalt. Asphalt is made up of grains of plastic produced from unsorted plastic waste, which replaces the sand and gravel traditionally used in asphalt production. In testing, it was found that asphalt roads were far less vulnerable to wear and tear than traditional asphalt, because the asphalt emulsion bonded better with the plastic than with gravel or sand.

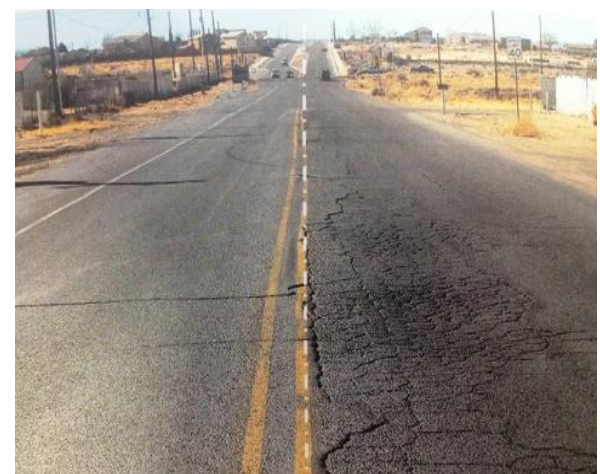

Fig. 1. The bit on the left is asphalt, the bit on the right is asphalt.

\section{Reinforcement of materials for construction finishes}

Construction finishing which includes painting, POP designs, fencing, glassing etc., can be alloyed with waste material. Rather than polluting the environment, a lot of waste is redeployed into useful applications. This study for example focuses on using water paper as an alloy for POP. What a cost reduction we will earn, while protecting the environment. Other waste substances can be used as special glass, alloy of paint, special metals etc.

\section{Newspaper Wood}

The wood is created by rolling up paper and solvent-free glue to create something not dissimilar to a log, then chopping it into usable planks. The wood can then be sealed so it is waterproof and flame-retardant, and used to build anything you would normally build with wood.

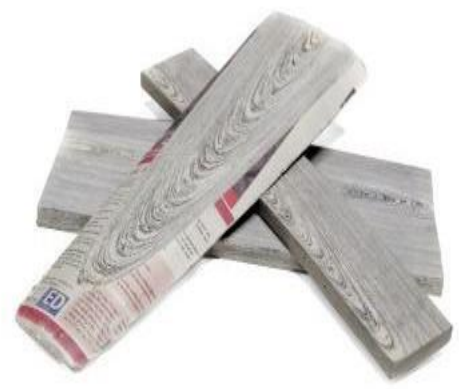

Fig. 2. Newspaper wood.

\section{Nappy roofing}

Special recycling plants separate out the polymers from the organic waste, and these polymers can then be used to create fibre-based construction materials like the tiles in the image below.

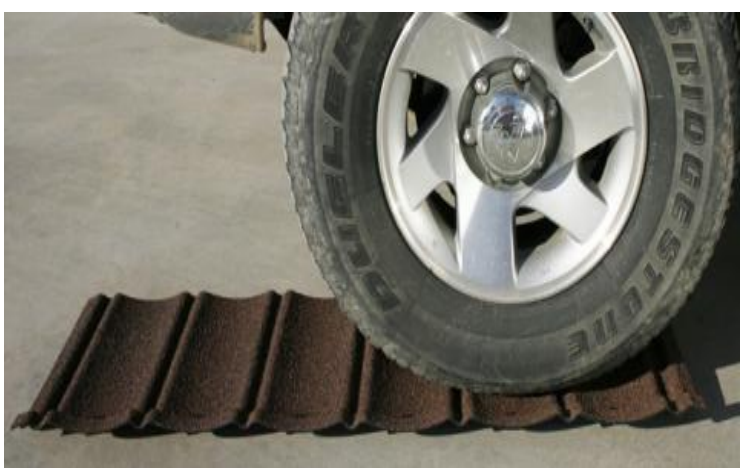

Fig. 3. Image: Lightweight tiles ltd.

\section{Blocks}

Old plastic bags, which are notoriously difficult to recycle in any other way can be used to make blocks for construction. Recycled bags or plastic packaging are placed in a heat mold and forced together to form the blocks. They're too lightweight to act as load-bearing walls, but can be used to divide up rooms or outdoor areas.

6. Mushroom walls

Here, designers figured out a way to grow wall insulator and packing materials using mycelium, a bacterium found in rotting organisms like tree trunks and agricultural by products. If placed in a mold, these organic matters grow to the desired shape within a couple of days and can then be stopped using a hot oven. This is particularly useful because traditional insulating and packing materials tend to be nonbiodegradable, or, in the case of asbestos, poisonous.

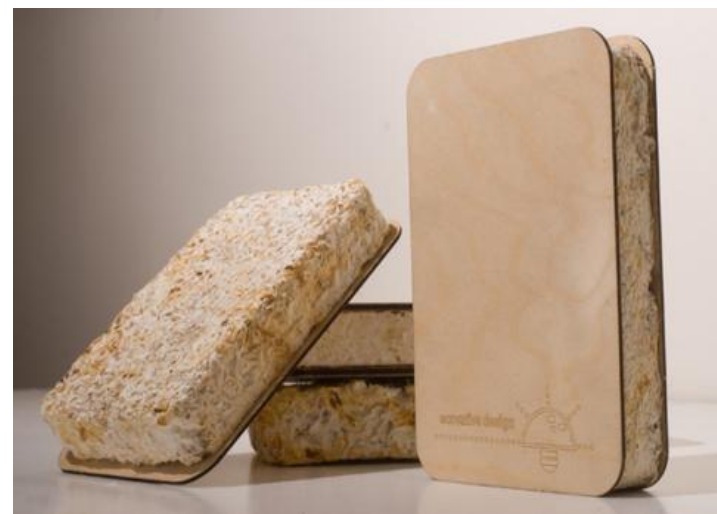

Fig. 4. Evocative designs.

\section{Wine cork panels}

These wall or floor tiles are made by combining recycled granulated cork with whole wine corks, which you can see as those oblong shapes in the tiles above. This is a pretty useful idea, considering the world apparently consumes around 31.7 bn bottles of wine a year.

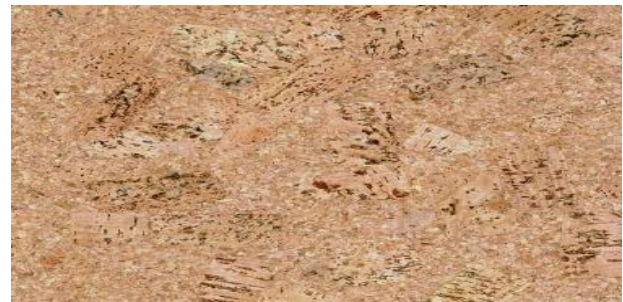

Fig. 5. Wine cork Panels. 


\section{LITERATURE REVIEW}

\section{A. Definition of Plaster of Paris}

Plaster of Paris is a type of plaster or binder which can be used in art, architecture, fireproofing, and medical applications. It is formed by heating gypsum to about $128^{\circ}$ $150^{\circ}$, where gypsum loses part of its water of hydration and is converted into POP, CaSO4.yH2O. Finely ground POP, when moistened with water, sets in a short time into a hard mass of gypsum, the rehydrated crystals forming and interlocking in such a way as to cause expansion in volume.

\section{B. History of POP}

History seems to indicate that, despite the name, POP was invented by the Egyptians and it was used as an artistic decoration in many Egyptian tombs and the Greeks picked up the technique using plaster in their own homes, temples and works of art. Paris became synonymous with this type of plaster in the 1600s. Thanks to a large deposit of gypsum which made it easy to produce POP [5].

Plaster of Paris is a type of plaster which can be used in art, architecture, fireproofing, and medical applications. When people think of plaster they are often thinking specifically of POP, although there are a number of different types of plaster on the market including lime plaster and cement plaster. Many arts and construction supply stores sell POP, and it can also be ordered through specialty companies. This plaster is made by calcining gypsum (CG) a process which involves exposing the gypsum to very high temperatures to create calcium sulphate and then grinding it into a fine powder. One advantage of POP is that there is no volume loss, so casts made with this plaster are true to the size of mould.

\section{Uses of POP}

POP is intensively used in the ceramic industries for the preparation of models and moulds. It is also used as the main raw material for manufacturing the $2,320 \mathrm{~kg} / \mathrm{m}^{3}$, so a concentration on setting would be expected, but the arrangement of the crystals is such that setting results in a slight expansion of about $0.5 \%$ [8].

\section{Reaction of POP with Water}

When water is added to dry POP, the water molecules incorporate themselves into crystalline lattice of the following:

- Statues;

- Toys;

- Chalks, crayons;

- Plastering of internal and external walls;

- Gypsum plaster board;

- Decorative picture frames and a wide range of applications in the interior decoration of buildings and other establishments.

POP is a type of plaster which can be also used in art works, architecture, Fire proofing and medical applications [2].

\section{E. POP as a Model Material for Brittle Porous Solids}

POP is a brittle solid with fracture properties which resemble those of cement, sand, stone, and other porous ceramics. It can be shaped easily and used as a model material to study the behaviour under load of porous solids containing macroscopic cracks, holes, and reinforcements. Gypsum is a natural mineral or sedimentary rock, which settles through the evaporation of sea water, trapped in lagoons with chemical name calcium sulphate. Chemists write it as: $\mathrm{CaSO}_{4} \cdot 2 \mathrm{H}_{2} \mathrm{O}$. POP is made by heating gypsum between $120^{\circ} \mathrm{C}$ and $150^{\circ} \mathrm{C}$. When POP is mixed with water the reverse reaction takes place. Water is reabsorbed leading to the formation of gypsum. The reaction is exothermic and results in a coherent mass of interlocking needle-shaped gypsum crystals. The chemistry of the reaction requires only $18.6 \%$ of water content for rehydration, but in practice much more is used to give the fluidity needed for casting. The excess water evaporates leaving considerable porosity. The true density of POP (hemihydrates) is about $2,320 \mathrm{~kg} / \mathrm{m}^{3}$ and of gypsum (dehydrate) is about calcium sulfate dehydrate, then giving up most of their kinetic energy in the form of heat. This hydration process converts the weak and powdery POP into a homogeneous rock of hard mass. When water is added to the powder it makes slurry. The slurry can be molded in a variety of ways and as it sets, a firm matrix is formed, creating a solid shape which is also very smooth.

The amount of water added to POP during mixing is critical:

- too little water can result in a powdery cohesion and a tendency to crumble and crack.

- too much water produces a porous material that is weak and fragile. Other substances like fibers are sometimes added to plaster to provide strength, color, and ease of working.

POP, when mixed with ordinary water becomes a liquid that gets gradually thicker and thicker until it becomes plastic, then turns to a paste, then a cheese boded mass; finally turns into a rock in about an hour. When plaster turns from liquid to solid, it does not shrink; rather, it expands [5]. It should be noted that, when mixing POP, it is always advisable to add POP to water. Never add water to POP.

\section{F. Utilization of $P O P$}

When mixing plaster, mix only as much as you will be able to use before it sets up. If you are making more than one track or samples, remember to always thoroughly wash all utensils and mixing containers between batches of plaster. The residue of partially hardened plaster in the mixing container will affect the chemical composition of the new mixture and cause the plaster to set up incorrectly. This will always result in a soft chalky cast. Therefore, it is important to wash away all traces of the previous mixture from your tools. You should use about two parts of plaster to one part of water. For example, two cups of plaster should be mixed with one cup of water. The consistency should be like that of pancake batter, or thick motor oil. It is recommended that you add the plaster to the water and begin mixing immediately. Plaster begins to set as soon as it comes in contact with water, so work quickly. If you use premeasured quantities, add the plaster to the water all at one time, and begin stirring immediately, this will give you the best results. Stir it for 3 to 5 minutes and get rid of all the lumps [9].

\section{G. Mechanical Properties of POP}

The Mechanical properties of POP depend on the powderto-water ratio, curing time, temperature, and pressure, and on post-cure heat treatment [2], [10]. These Mechanical 
properties are made up of Young modulus, flexural or tensile strength, compressive strength, modulus of rupture and fracture toughness [2], [10].

\begin{tabular}{cc} 
TABLE I: THE MECHANICAL PROPRIETIES OF POP \\
\hline Mechanical properties & Values \\
\hline Workability time (min) & $60-90$ \\
Final setting time (min) & 150 \\
Compressive strength $(\mathrm{MPa})$ & 2.5 \\
Flexural strength $(\mathrm{MPa})$ & 1 \\
Dry density $\left(\mathrm{kg} / \mathrm{m}^{2}\right)$ & $650-1000$ \\
$1000 \mathrm{~m}(\%$ passing) & 100 \\
$150 \mathrm{~m}(\%$ passing) & 60 \\
\hline
\end{tabular}

\section{H. Fiber Fineness}

The fineness (or titer $\mathrm{T}$ ) of a fiber describes the mass per unit length. Therefore, it depends on the diameter $\mathrm{d}$ of the fiber and its density $\rho$ (see section below). The unit for fiber fineness is tex (grams per 1,000 m) or den (grams per 9,000 $\mathrm{m})$. The following equation can be used to calculate the fineness from filament diameter or vice versa.

$$
D=\sqrt{\frac{4}{\pi \rho} T}
$$

\section{Physical Properties of POP}

When we talk on physical properties of gypsum plaster, we talk on the density, strength, colour, setting time etc. See Table II

\begin{tabular}{cc}
\multicolumn{2}{c}{ TABLE II: THE PHYSICAL PROPRIETIES OF POP } \\
\hline Physical Proprieties & Values \\
\hline Density g/cm & $\sim$ \\
Strength MOR N/mm & $\sim$ \\
Colour extra white $(\%)$ & $\sim$ \\
Sieve Res \% (120) & $\sim$ \\
Initial setting time (minutes) & $3-5$ \\
Final setting time(minutes) & $15-17$ \\
\hline
\end{tabular}

\section{J. Advantages and Disadvantages of Using Pop in Construction}

\section{Advantages}

Plaster of Paris is a useful material in construction because it is:

- Durable and hard;

- Fire resistant;

- Sound resistant;

- Fast to install;

- Easy to repair;

- Light weight;

- Inexpensive compared to the others;

- Excellent substrate for paint, fabric, and wood.

2. Disadvantages

The disadvantages of POP are as follows [8]:

- Untreated face paper can encourage mould growth;

- Not resistant to water;

- Not structural;

- Reflects sound;

- Lacks intrinsic characteristics.

\section{K. Tensile Properties of Paper}

The tensile properties of paper are measured by clamping a strip between two grips and applying a tensile load until the strip breaks (ISO 1924-3:05). The applied load and the elongation are constantly measured throughout the test. Tensile properties, which is the scientific term for strength properties, include tensile strength, stretching, strain at break, Young's modulus, stiffness, and elongation. The tensile index is also common when comparing papers, because it includes the grammage of the paper as well.

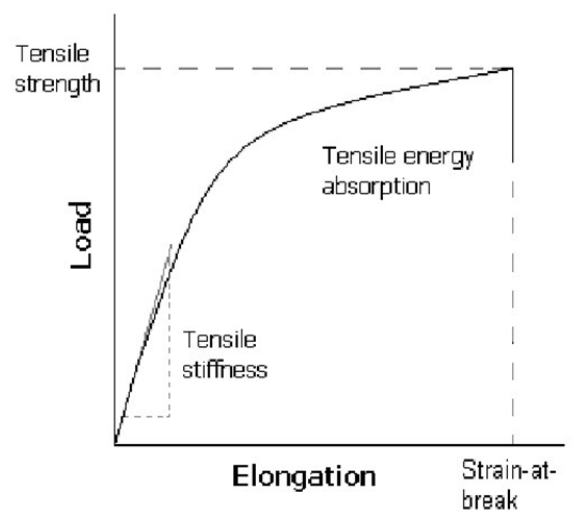

Fig. 6. Schematic sketch of a typical load elongation curve for paper for the determination of tensile strength, tensile stiffness, tensile energy absorption and strain at break.

The curve shows where the load is plotted versus the elongation. Stress is the force required to elongate unit cross sectional area of the material, but in the paper literature, the term stress is often used for force divided by width, since paper is a porous material, and the thickness includes also the voids that do not contribute to strength. The elongation can be reported as a fraction, the elongation divided by the original length, or as a percentage, the fractional elongation multiplied by 100 . Factors affecting the test results are grip pressure, specimen size, strain rate, moisture content and temperature.

\section{MATERIALS AND METHODS}

\section{A. Experimental Design of Process Parameters}

Experimental designs nowadays have been regarded as one of the most favorable techniques in covering a large area of practical statistics and obtain unambiguous results with the least expense. An experiment is a series of tests, called runs, in which changes are prepared in the input variables in order to recognize the reasons for changes in the output response. Design of experiments is a powerful technique used for exploring new processes; gaining increased knowledge of the existing processes and optimizing these processes for achieving world class performance and enable designers to determine simultaneously the individual and interactive effects of many factors that could affect the output results in any design.

Optimizing refers to improving the performance of a system, a process, or a product in order to obtain the maximum benefit from it. Often engineering experimenters wish to find the conditions under which a certain process 
attains the optimal results.

By careful design of experiments, they want to determine the levels of the design parameters at which the response reaches its optimum. The optimum could be either a maximum; a minimum or target responses which is influenced by several independent variables (input variables). One of methodologies for obtaining the optimum results is response surface methodology.

Response surface method (RSM), invented by Box and Wilson, is defined as a collection of mathematical and statistical tools or techniques useful for modeling, analyzing and simultaneously solving problems in which a response of interest is influenced by several variables and the objectives is to optimize this response.

\section{B. Basics of Stress Analysis}

We briefly study the basics of solid mechanics, which are essential to understand when materials break. This is important in construction engineering in the usage of plaster of Paris (Gypsum plaster) reinforced with paper pulp, where we usually do not want the material to break or fail prematurely; it is important in manufacturing, where most operations, e.g., cutting, are done by essentially 'breaking' the material. Essentially, any load applied to a solid will induce stress throughout the solid. There are two types of stresses: shear and tensile/compressive, as shown in the figure below. Consider that some force(s) are applied to a solid such that it is experiencing stress but is in stable equilibrium.

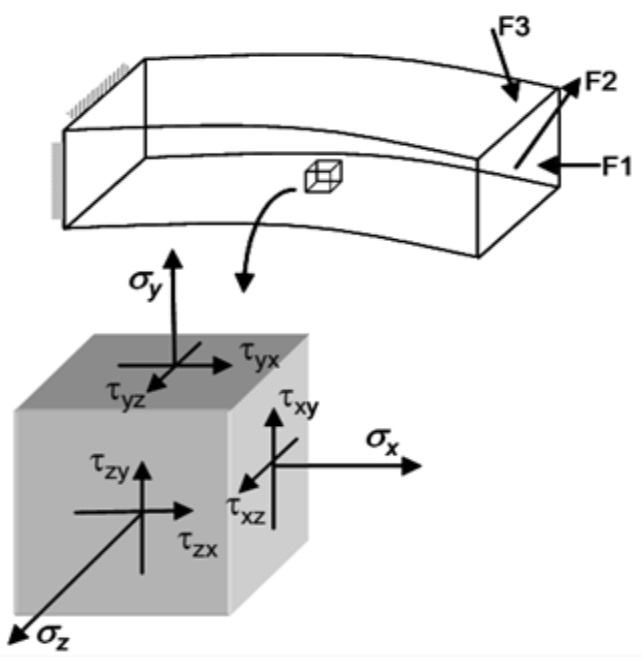

Fig. 7. Stresses in a infinitesimal element.

The question we need to answer is: under some given set of stresses as shown, will the material fail? To simplify matters, let us look at the 2D situation (XY plane only). To answer our question, we first find the resultant stresses, $\sigma$ and $\tau$, along some arbitrary direction inclined at angle $\varphi$ to the $y$ axis (see Fig. 8). Since the element is at equilibrium, the resultant of all forces must balance. Also, by definition, stress $=$ force/area. From this, we get the following relation:

$$
\begin{aligned}
& \sigma=\frac{\sigma_{x}+\sigma_{y}}{2}+\frac{\sigma_{x}-\sigma_{y}}{2} \cos 2 \theta+\tau_{x y} \sin 2 \theta \\
& \tau=\frac{\sigma_{y}-\sigma_{x}}{2} \sin 2 \theta+\tau_{x y} \cos 2 \theta
\end{aligned}
$$

Differentiating (2) and equating to zero, we get:

$\tan 2 \theta=\frac{2 \tau_{x y}}{\sigma_{x}-\sigma_{y}}$

\section{Ultimate Tensile strength (UTS)}

As we keep increasing the load in the plastic range, at some point, the material suddenly loses strength, and some cross section becomes very narrow and elongates freely (necking). The maximum stress that it could withstand is the UTS.

In the linear elastic range, we get Hooke's law:

or

$$
\sigma=\text { E.e }
$$

$$
\mathrm{E}=\sigma / \mathrm{e}
$$

where $E$ is a constant called Young's modulus of the material. $\mathrm{E}$ is large $=>$ material is stiff; if it is small, the material is elastic.

Another interesting effect is noticed when we stretch a material into the plastic range, and then release it.

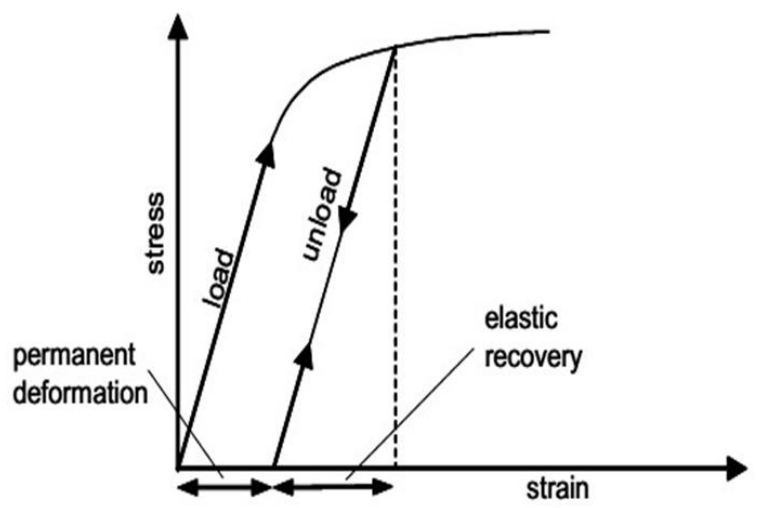

Fig. 8. Elastic recovery after plastic deformation.

\section{Toughness}

Toughness is an estimate of how much energy is consumed before the material fractures. Energy consumed $=$ work done $=$ force $\mathrm{x}$ distance - which you can easily see, is related to the stress and strain. So:

$$
\begin{gathered}
\text { Toughness }=\text { the strain energy = area under the stress } \\
\text { strain curve }
\end{gathered}
$$

To compute toughness, True stress and True strain are used, which measure the instantaneous stress strain at each point in the $\sigma-\varepsilon$ curve.

Strength of a material is an estimate of the height of the $\sigma^{-} \varepsilon$ curve, while toughness accounts for both, the height, and the width of the curve.

\section{E. Ductility}

Ductility is a measure of how much the material can be stretched before it fractures. A simple measure of ductility is:

$$
\text { Ductility }=100 \times(L f-L o) / L o
$$




\section{F. Hardness}

There is no precise definition of hardness. We shall take it to mean "resistance to plastic deformation under load". Under this definition, it is measured by the permanent deformation on the surface of the material being tested, when subjected to a standard loading. There are several different hardness tests that have been developed over the years. One of the earliest is the Mohs scale.

\section{G. Failure in Compression}

Most materials are much stronger in compression than in tension. If a cylindrical sample is subjected to compression at the two ends, it will usually fail by a process called buckling. If the compressive force is totally uniform, then the material can stand very high stress; however, since either the stress, or the material properties are not precisely uniform, and so at some intermediate stage, the sample will bend an infinitesimal amount in the middle; as soon as this happens, the bending moment creates tensile stresses in that region, and the cylinder suffers immediate failure.

\section{H. Torsion}

Torsion is a twisting force, called a moment, applied (usually) to a bar. It introduces a shear stress in the material. Consider a solid cylindrical bar at equilibrium and subjected to torsion as shown in the figure below. A torque $\mathrm{T}$ is applied to it, causing it to twist by an angle of $\theta$ over the length L. Initially, the bar remains in the elastic deformation range. Then, due to symmetry, every planar cross-section parallel to the end-faces in the bar gets twisted but remains planar. So, there is a pure shear in the interface between any imaginary cross-section plane. Also, every radial line in the solid is turns around the axis but remains as a straight line. For such a bar, the shear stress is maximum at the surface and zero at the center along the axis. The stress increases linearly along the radius, and the following relations hold:

\section{Angle of twist: $\theta=$ TL/GJ}

Shear stress: $\tau=\operatorname{Tr} / \mathbf{J}$

Maximum shear stress $=\tau_{\max }=\mathrm{TR} / \mathrm{J}$

Shear strain $=\gamma=r \theta / L$

where $\mathrm{T}=$ torque, $\mathrm{L}=$ cylinder length, $\mathrm{r}=$ distance from axis of the cylinder, and $\mathrm{R}=$ radius of the cylinder, $\mathrm{J}=$ polar moment of inertia of the cross section of the bar and is computed as $\mathrm{J}=\int \mathrm{r}^{2} \mathrm{dA}$.

For a solid cylinder $\mathrm{J}=\pi \mathrm{d}^{4} / 32$.

For a hollow cylinder with outer diameter $\mathrm{D}$ and inner diameter $\mathrm{d}, \mathrm{J}=\pi(\mathrm{D} 4-\mathrm{d} 4) / 32 \mathrm{G}$ is a constant called the modulus of rigidity.

Because the stress and strain vary along the radius, failure begins at the outer surface. It is conventional to measure torsion properties using a thin, hollow cylinder, since for such a part, the shear stress across the cross section is nearly constant.

\section{Mixture Design}

\section{Consistencies of Water Content in Paper Paste}

The crushing of the paper paste was aided by a sieve of $5 \mathrm{~mm}$ which contained water, then the drying process was done with the use of the following materials:

- An electronic balance of $500 \mathrm{~g}$;

- A sample of paper paste;

- An artificial air drying oven.

Procedure:

Water is put into the mixer basin; then POP is poured at the same time with the paper paste while mixing manually.

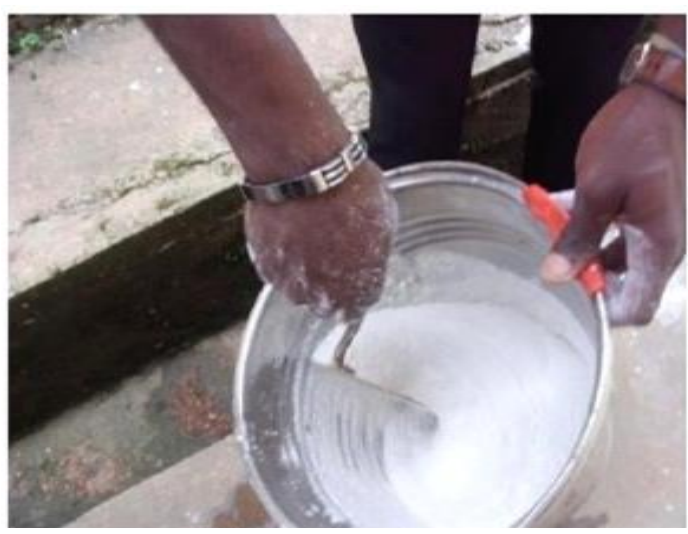

Fig. 9. Manual Mixer.

The mixing is done at once after water must have been introduced. POP and paper paste are stirred for $35 \mathrm{~s}$ with a very fast speed because POP reacts very fast when it is mixed or comes in contact with water.

Mixing was stopped after $35 \mathrm{~s}$, then the mixture was rapidly put into the mould during a short period of time (about 25 seconds).

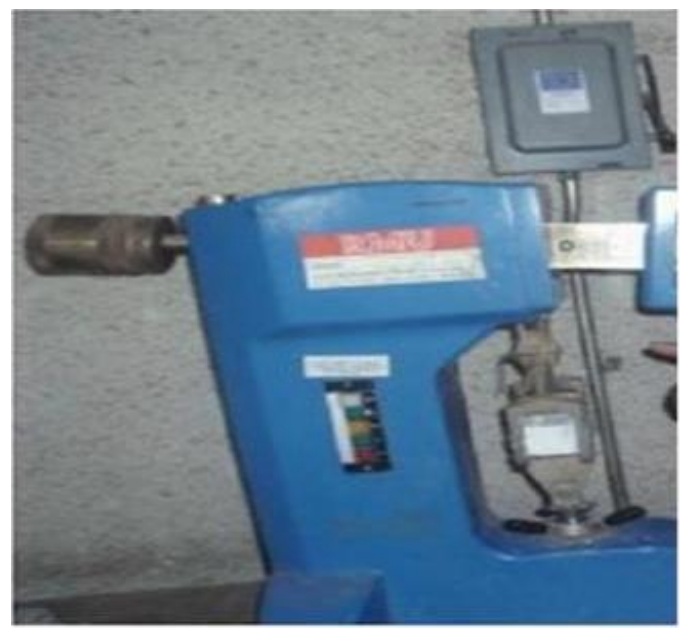

Fig. 10. Hydraulic press (flexural strength machine)

\section{RESULTS AND DISCUSSIONS}

\section{A. Interpretation of Results}

In this chapter, the various results obtained from this research will be examined, particularly on the influence of paper pulp on POP when working, the time of hardening, the shrinkage, flexural strength, compression, and the apparent density of mixtures.

Note on Volume maintenance

After having all the samples of the POP reinforced with 
waste paper and that of a normal paste at different percentages of mixture, it was discovered that, there was no volume loss in all the samples. Shrinkage did not occur in any of the samples.

The water content of samples not containing paper paste is $36.96 \%$ which is lesser than those containing paper paste. This is to say that the water content is gradually increasing when the paper paste is added to the plaster paste. This is because; paper paste contained already moisture in it before mixing with the POP paste up to $80 \%$ and $100 \%$ of mixtures where it maintained the same water content.

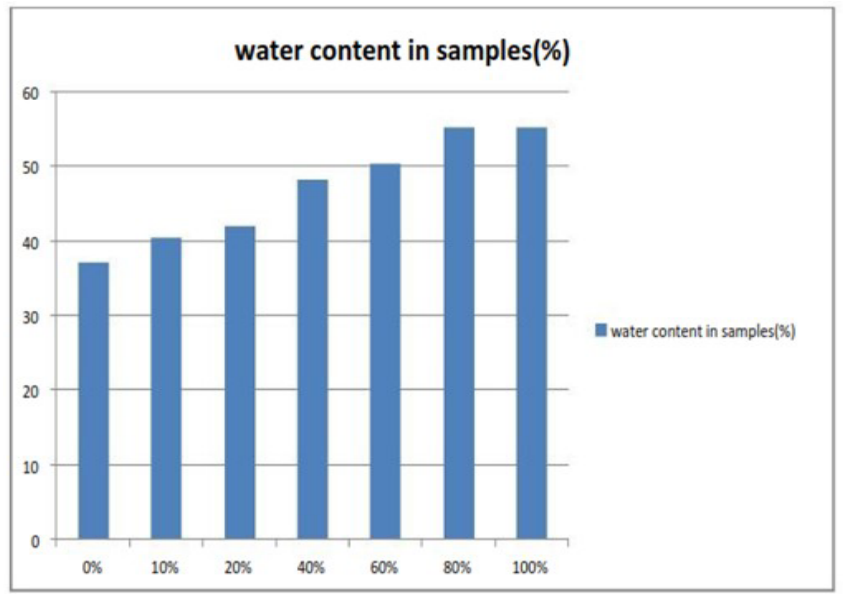

Fig. 11. Water content in samples strength.

The time of setting from the beginning of mixing to the end of hardening increases the more the paper paste is added into the mixture and also the material becomes lighter when it is finally dry.

Mixing POP with paper pulp solves the problem of cracking considerably.

The compressive strength decreases when we increase the percentage of the paper paste. That is in agreement with the available literature.

Indeed, most authors have reported that, the addition of vegetable fibres to plasters, concrete or mortar does not improve its compressive. But in this study, we saw that the containing and not containing paper paste incorporation of a small quantity of the paper pulp ( $\mathrm{k} 0$ approximately $10 \%$ ) decreases the compressive strength and makes it fall below that of the normal plaster of $0 \%$, thereby making its resistance to drop.

The flexural strength improves with incorporation of a small quantity of the paper paste ( $\mathrm{k} 0$ approximately $10 \%$ ) compared to the standardized plaster. The flexural strength then gets to fall with further additions until it gets below that of the normal POP. This makes the resistance to fall as the paper paste increases in the plaster paste.

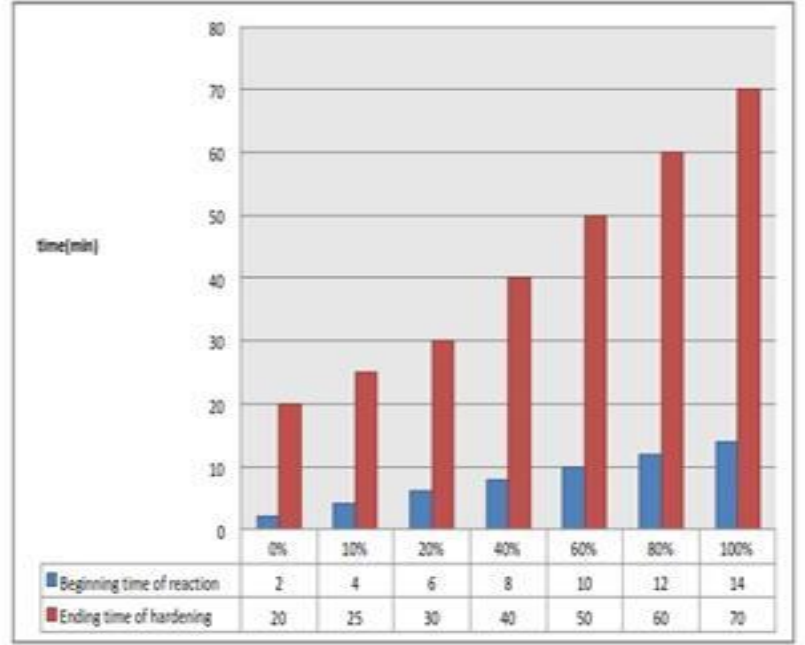

Fig. 12. The influence of the paper pulp over the time of hardness of POP cement.

The apparent density decreases and varies between 1,035.6 and $621.2 \mathrm{~kg} / \mathrm{m}^{3}$ according to the paper mixtures. These results make us to affirm that we reduce the weight of the material making it lighter, thus it is more liable to wear out. We also see that it can be suitably used for the manufacture of light weight panels. The use of this new material can be very important for the manufacture of elements pulp.

\section{CONCLUSIONS AND RECOMMENDATIONS}

This work consisted in studying the physico-mechanical properties of POP reinforced with paper which is very important for the manufacture of elements pulp. From this study, we can draw the following conclusions:

- The incorporation of paper pulp or paper paste in literature review and has good soundproofing the formulation of plaster paste causes a quality, thus, paper in the plaster paste has good considerable drop in the workability of the plaster phonic insulation. The results obtained at the end of these investigations can enable customers to draw up a technical card of specifications for this new material.

- Since paper pulp is waste product and cheaply available, this material will go a long way to reduce the cost of POP and therefore extend its use in third world countries.

\section{REFERENCES}

[1] Guth, W., and Tety, R. (1992). Ultimatum bargaining Behaviour. A survey and comparison of experimental results'J. Econ Psych 11,417449

[2] Eckel, (1996). Chivalry and Solidarity in Ultimatum Game,'Virgina Polytectnic Institute and State Univerity

[3] Lafarge P. R. (27 November 2008) Staff CaSO4, 1/2 $\mathrm{H}_{2} \mathrm{O}$.

[4] Bledeki, (1999). Rapid design and fielding of four diagnostic technologies

[5] Mullick, (1999). Measuring Universl Design:

[6] Chapman and Hall (1993). Journal of Material Science 28, United States Gypsum Company (2000), Plaster Mixing Procedures.

[7] Google. (s.d.). Reaction of Plaster of Paris.

[8] Lafarge, (2000). Lafarge net earnings in 1999: +32\% I Lafarge Holcm.cm

[9] Heidrich O, Bird RN, Huang Y. (2007), The Application of Recycled Waste Materials in the Construction of Asphalt Pavements.

[10] Christopher Pardell (2000), Working with Plasters. United States Gypsum Company (2012) Sheetrock ${ }^{\circledR}$ Plaster of Paris. 
[11] Thesis of doctorate Insa of Lyon France (1988). The Study of the Construction of fibre dispersed anisotropic in the cement mortar on the laws of behaviour, the criteria of resistance and Cracking of Materials.

[12] CJ Liebenberg (2007), Waste recycling in developing countries in africa: barriers to improving reclamation rates.

[13] Jimenez A. R. et al. (2014) Construction and Building Materials.

[14] Danh D. B, rice husk ash as a mineral admixture for high performance concrete.

[15] Arikana M., K. Sobolevb, received (15 May 2001) accepted 6 May 2002 The optimization of a gypsum-based composite material *Civil Engineering Department, Middle East Technical University, Ankara, Turkey Civil Engineering Department, European University of Lefke, Gemikonagi Lefke via Mersin 10, KKTC, Turkey.

[16] Panaitescu D, Mihaela and Al. (2007). L'effet de l'interface dans les composites de fibres naturelles et de matières plastiques. Revue Roumaine de Chimie, pages

[17] Singh M. C. M. (1992) Glass fibre reinforced water-resistant gypsumbased composite. Cement Composites

[18] Hernandez-Olivares F, Oteiza I., and de Villanueva L. (1992). Experimental analysis of toughness and modulus of rupture increase of sisal short fiber reinforced hemi-hydrated gypsum. Composite Structures

[19] Sophie E. (2003) Comportement à la prise et caractérisation mécanique de matériaux composites à base de plâtre. $\mathrm{PhD}$ thesis, Université de Caen, Encarta. (2009). Paper. Files.

[20] Google.

(s.d.).Récupérésurhttp://www.notreplanete.info/actualities/actu_910_ paper_recycle.php.

[21] Kriker. (2005). Characteristics of fibre of death palm and their properties.

[22] Pardell, C. (2000). Working with Plasters.

[23] WBDG National Institute OF Building Sciences (2000). Plaster and Gypsum Boards.

[24] United State Gypsum Company. (2000) Plaster mixing procedures

[25] United State Gypsum Company (2012). Sheetrock Plaster of Paris.

[26] Wikipedia. (2014, March 20). Récupéré sur How to eliminate inks at the time from the reprocessing of paper: Brittany durable mountain development.

[27] Wikipedia. (2014, February 15). Récupéré sur papercarton/waste/collect, storage, regional treatment and elimination of waste/ observatory of the industrial waste in the mdday-pyrenees.

[28] Wikipedia. (2014, February 15). Récupéré sur Recycled paper, a good idea recuo.

[29] www.alibaba.com. (2014, June 13). Récupéré sur External cement ceiling panel. 